\title{
PB2 segment promotes high-pathogenicity of H5N1 avian influenza viruses in mice
}

\author{
Hailiang Sun, Pengfei Cui, Yafen Song, Yan Qi, Xiaokang Li, Wenbao Qi, Chenggang Xu, \\ Peirong Jiao * and Ming Liao *
}

College of Veterinary Medicine, South China Agricultural University, Guangzhou, China

\author{
Edited by: \\ Mei-Ru Chen, National Taiwan \\ University, Taiwan \\ Reviewed by: \\ Chi-Ju Chen, National Yang-Ming \\ University, Taiwan \\ Sui-Yuan Chang, National Taiwan \\ University, Taiwan \\ *Correspondence: \\ Peirong Jiao and Ming Liao, College \\ of Veterinary Medicine, South China \\ Agricultural University, 483 Wushan \\ Road, Guangzhou 510642, China \\ e-mail:prjiao@yahoo.com; \\ mliao@scau.edu.cn
}

H5N1 influenza viruses with high lethality are a continuing threat to humans and poultry. Recently, H5N1 high-pathogenicity avian influenza virus (HPAIV) has been shown to transmit through aerosols between ferrets in lab experiments by acquiring some mutation. This is another deeply aggravated threat of H5N1 HPAIV to humans. To further explore the molecular determinant of H5N1 HPAIV virulence in a mammalian model, we compared the virulence of A/Duck/Guangdong/212/2004 (DK212) and A/Quail/Guangdong/90/2004 (QL90). Though they were genetically similar, they had different pathogenicity in mice, as well as their 16 reassortants. The results indicated that a swap of the PB2 gene could dramatically decrease the virulence of rgDK212 in mice (1896-fold) but increase the virulence of rgQL90 in mice (60-fold). Furthermore, the polymerase activity assays showed that swapping PB2 genes between these two viruses significantly changed the activity of polymerase complexes in 293T cells. The mutation Ser715Asn in PB2 sharply attenuated the virulence of rgDK212 in mice (2710-fold). PB2 segment promotes high-pathogenicity of H5N1 avian influenza viruses in mice and 715 Ser in PB2 plays an important role in determining high virulence of DK212 in mice.

Keywords: influenza virus, H5N1, virulence, reassortant, mutants, mice

\section{INTRODUCTION}

Recent research has confirmed that obtaining human receptor binding specificity and enhancing the polymerase activity enabled the $\mathrm{H} 5 \mathrm{~N} 1$ virus to achieve aerosol transmission between ferrets (Herfst et al., 2012; Imai et al., 2012). This may allow novel H5N1 virus to become the next pandemic. H5N1 HPAIV is a continued threat to public health (Chen et al., 2004, 2005, 2006; Li et al., 2010; Wan et al., 2011). Therefore, it is pertinent to continue studying the pathogenesis mechanism of $\mathrm{H} 5 \mathrm{~N} 1$ HPAIV.

Several genes are confirmed as contributing to the virulence and replication of $\mathrm{H} 5 \mathrm{~N} 1$ viruses. The PB2 and NS genes play an important role in determining the pathogenicity of the influenza virus to a host. Specific adaptation of polymerases was important in determining viral host range and virulence (Hatta et al., 2007; Neumann et al., 2007). Mutations occurring at key positions in $\mathrm{PB} 2$, such as $158,271,627$, and 701 , could significantly enhance the replication of $\mathrm{H} 5 \mathrm{~N} 1$ influenza A virus in mammalian cells as well as pathogenicity and transmission in animal models (Hatta et al., 2001; Li et al., 2005; Gao et al., 2009; Bussey et al., 2010; Zhou et al., 2011). The virus' capability to inhibit $\alpha / \beta$-interferon production obviously affected its level of virulence to its host. The length of NS1 protein or mutation at position $92 / 42$ affected the virulence of viruses in mice and pigs by inhibiting production of host interferon (Seo et al., 2002; Quinlivan et al., 2005; Jiao et al., 2008). The PB1-F2 Asn66Ser variant also reduced the production of host IFN $\alpha / \beta$ (Conenello et al., 2007). In addition, mutations at receptor binding sites and disappearance of $\mathrm{N}$-glycosylation motif in HA protein affected the binding feature and virulence (Hatta et al., 2001; Maines et al., 2006; Chen et al., 2007; Tumpey et al., 2007; Yen et al., 2007a; Gao et al., 2009; de Wit et al., 2010). Mutations in the M1 and NA genes could possibly promote viral replication in mammalian cells and enhance the lethality of the virus in mice (Yen et al., 2007b; Fan et al., 2009; van Wielink et al., 2012).

However, the mammalian pathogenic mechanism of $\mathrm{H} 5 \mathrm{~N} 1$ HPAI virus is still not clear. In this study, we explored the molecular determinants of different virulence in mice between DK212 and QL90, by engineering single segment swap reassortant viruses and single amino acid mutation viruses using reverse genetics technology.

\section{MATERIALS AND METHODS VIRUS, SEOUENCE, AND MOUSE}

DK212 and QL90 and high-pathogenicity H5N1 influenza viruses were isolated from ducks/quails in China, purified and propagated in 9- to 11-day-old specific-pathogen-free (SPF) embryonic hen eggs, and stored at $-80^{\circ} \mathrm{C}$. Viral RNA was extracted from allantoic fluid with the RNeasy Mini kit (Qiagen) and reverse transcribed with Superscript III (Invitrogen) by using the primer of 12 units. PCR amplification was performed using a set of special primers (Hoffmann et al., 2001). PCR products were purified using the PCR Purification Kit (Promega) and sequenced by Shanghai Invitrogen Biotechnology Co., Ltd. Sequenced data were compiled with the SEQMAN program of Lasergene7 (DNASTAR). According to the characteristics of the 
Table 1 | Amino acid differences between DK212 and QL90.

\begin{tabular}{|c|c|c|c|c|c|c|c|c|}
\hline \multirow{2}{*}{$\begin{array}{l}\text { Gene } \\
\text { PB2 }\end{array}$} & \multicolumn{8}{|c|}{ Difference and position of amino acids } \\
\hline & GIn $^{a} 39^{b}$ Lys $^{c}$ & Thr339Lys & Arg340Lys & Gly368Arg & Ile649Val & Thr684Ala & Ser715Asn & $-d$ \\
\hline PB1 & Arg353Lys & - & - & - & - & - & - & - \\
\hline PA & Leu261Phe & Asn296Ser & Glu327Gly & Thr337Ala & Val354lle & Lys544Glu & Asn648Ser & Ser653Pro \\
\hline HA & Ser100Asn & Ala143Thr & Leu154GIn & Pro157Ser & Thr172Ala & Lys205Arg & Asn289Ser & - \\
\hline NP & - & - & - & - & - & - & - & - \\
\hline NA & - & - & - & - & - & - & - & - \\
\hline M1 & Met59lle & - & - & - & - & - & - & - \\
\hline M2 & Pro25Leu & Ser31Asn & Glu66Ala & Asn82Ser & - & - & - & - \\
\hline NS1 & Val129Phe & Tyr133Phe & Asp166Gly & Asn201Ser & - & - & - & - \\
\hline NS2 & Met14Val & Met49Val & Ile83Val & Thr115Ala & - & - & - & - \\
\hline
\end{tabular}

a The amino acid at corresponding position of DK212.

${ }^{b}$ The position at which amino acids of the two viruses is different.

${ }^{c}$ The amino acid at corresponding position of QL90.

${ }^{d}$ The protein sequence of DK212 is same to that of QL90.

HA antigen, DK212 belonged to Clade 9 (Sun et al., 2011), and QL90 was in Clade 1. The two viruses shared the same NA and NP genes but displayed 36 differences at the amino acid level in other six genes (Table 1). Six-week-old, female SPF BALB/c mice were purchased from the Laboratory Animal Center of South China in Guangzhou.

\section{GENERATION OF VIRUSES}

The cDNA of genes from DK212 or QL90 were amplified by a set of primers (Supplementary Tables 1,2), and inserted into a $\mathrm{pHH}$ vector using ESP3I enzyme cutting sites. Single mutations were introduced into the PB2 gene by QuikChange II XL Site-Directed Mutagenesis (Agilent Technologies) with a set of primers (Supplementary Table 3). Viruses were rescued by using an eight-plasmid reverse genetics system (Hoffmann et al., 2000). The viruses obtained from cloned DK212 or QL90 cDNA were designated rgDK212 and rgQL90, respectively. The viruses bearing the PB2, PB1, PA, HA, NA, NP, M, or NS gene of QL90 and the other seven genes of DK212 were designated 212-90PB2, 212-90PB1, 212-90PA, 212-90HA, 212-90NP, 212-90NA, 212$90 \mathrm{M}$, and 212-90NS, respectively. The viruses bearing the PB2, PB1, PA, HA, NA, NP, M, or NS gene from DK212 and the remaining genes from QL90 were designated 90-212PB2, 90212PB1, 90-212PA, 90-212HA, 90-212NP, 90-212NA, 90-212M, and 90-212NS, respectively. Mutant DK212 viruses containing a substitution of the PB2 amino acid residue at position Gln39Lys, Ile649Val, Thr684Ala, and Ser715Asn were designated 212Gln39Lys, 212-Ile649Val, 212-Thr684Ala, and 212-Ser715Asn. Likewise, mutant QL90 viruses were designated 90-Lys39Gln, 90Val649Ile, 90-Ala684Thr, and 90-Asn715Ser, respectively. Rescued viruses were then sequenced to conclude that there was no unwanted mutation.

\section{PATHOGENICITY OF VIRUSES TO MICE}

To evaluate the pathogenicity of these viruses in mice, 6-weekold, female SPF BALB/c mice were randomly divided into groups of 8 mice. After being lightly anesthetized with $\mathrm{CO}_{2}$, the mice were intranasally inoculated with the corresponding viruses, at a dose of $10^{6} \mathrm{EID}_{50}$ in a $0.05 \mathrm{~mL}$ volume. Additionally, five mice inoculated with $0.05 \mathrm{~mL}$ PBS served as negative controls. Three mice in each group were euthanized at 3 days postinoculation (DPI) to determine virus titers in their brain, spleen, kidneys and lungs, as previously described (Chen et al., 2004). Virus titers were calculated as means \pm standard deviation in $\log _{10} \mathrm{EID}_{50} /$ gram of tissue by using SPASS (Version 11.5), and the data were analyzed using a One-Way repeated-measure analysis of variance (ANOVA) followed by Turkey and Duncan's multiple comparison test. The remaining mice were investigated daily for 14 days to observe weight loss and mortality. Variation of body weight was detected according to previous study ( $\mathrm{Li}$ et al., 2005; Jiao et al., 2008; Fan et al., 2009). Briefly, eight mice in group were weighed and then the total weight was divided by eight to get mean weight during 1-3 post infection days (DPI). After 3 DPI, total alive mice in the group were weighed and then divided the number of live mice to get meant weight. The mean body weight at time point minus the mean body weight at 0 DPI and then the result was divided the original mean body weight go get the percentage of weight loss. To detect the $50 \%$ mouse lethal dose $\left(\mathrm{MLD}_{50}\right)$ of viruses, seven groups of five mice each were infected with 10 -fold serial dilutions, from $1 \mathrm{EID}_{50}$ to $10^{6} \mathrm{EID}_{50}^{16}$. These mice were daily investigated and weighed for 14 days. Mice which lost more than $30 \%$ of their body weight were euthanized. MLD $_{50}$ were calculated using the Reed-Muench method (Reed and Muench, 1938).

\section{POLYMERASE ACTIVITY ASSAY}

To detect the polymerase activity of viruses, the plasmid pMD18T-NP-LUCI was constructed. In a brief explanation, the luciferase gene flanked with the non-coding region of $\mathrm{NP}$ of DK212 was amplified, using pGL-3 control (Promega) as template, by primer L-NPFL-NPR. It was then cloned into pMD18-T. $293 \mathrm{~T}$ cell was cultured in a 12-well plate overnight. When the monolayer formed approximate $90 \%$, they were transfected with $0.4 \mu \mathrm{g}$ of $\mathrm{pHH}-\mathrm{NP}, \mathrm{pHH}-\mathrm{PA}, \mathrm{pHH}-\mathrm{PB} 1$, and $\mathrm{pHH}-\mathrm{PB} 2$, and $0.1 \mu \mathrm{g}$ of pMD-18T-NP-LUCI, as well as $0.1 \mu \mathrm{g}$ pRL-SV40 
(Promega) as an internal control. After transfection for 24h, cell lysate was prepared and the luciferase yield was tested by using the dual-luciferase reporter assay system (Promega), with a single tube luminometer (Promega). Relative activity of the polymerase was normalized to Renilla gene expression. The results were calculated as means \pm standard deviations from three independent experiments, using SPASS (Version 11.5).

\section{BIOSAFETY AND ANIMAL HANDLING}

The laboratory and mice experiments were carried out under BSL-3 conditions in compliance with biosafety committee of South China Agriculture University approved protocols. The handling of mice was performed in accordance with experimental animal administration and ethics committee of South China Agriculture University approved guideline.

\section{RESULTS \\ THE VIRULENCE OF DK212 WAS STRONGER THAN OL90 TO BABL/C MOUSE}

To compare the pathogenicity of DK212 and QL90, mice were intranasally infected with the corresponding virus at a dose of $10^{6}$ embryo infective dose $50\left(\mathrm{EID}_{50}\right)$. DK212 quickly caused $23.97 \%$ body weight loss and killed all mice by 7 DPI at a dose of $10^{6}$ $\mathrm{EID}_{50}$. Virus was isolated from the brain, spleen, kidney, and lung, with a mean titer between 1.67 and $6.25 \log _{10}$ EID $_{50}$ on 3 DPI. Furthermore, the virus titer of DK212 was higher than that of QL90 in the brain and kidney $(p<0.05)$. Although QL90 caused $25.54 \%$ body weight loss and killed all the mice at 10 DPI in a dose of $10^{6} \mathrm{EID}_{50}$, the virus only replicated in the spleen and lungs with a mean titer between 3 and $5.83 \log _{10}$ EID $_{50}$ (Figures 1A,B and Table 2). The MLD 50 of DK212 was $1.5 \log _{10} \mathrm{EID}_{50}$, while the $\mathrm{MLD}_{50}$ of QL90 was $4.167 \log _{10} \mathrm{EID}_{50}$ (Table 3). The virulence of DK212 in mice was 464-fold higher than that of QL90.

The pathogenicity of the rescued viruses was similar to that of the wild-types. rgDK 212 caused $26.36 \%$ body weight loss and killed all the mice at $4 \mathrm{DPI}$ at a dose of $10^{6} \mathrm{EID}_{50}$, and replicated in four organs with a titer of 2.25-6.58 $\log _{10}$ EID $_{50}$. Meanwhile, rgQL90 caused $10.36 \%$ body weight loss and caused $100 \%$ of the mice to die by 9 DPI at a dose of $10^{6} \mathrm{EID}_{50}$ (Figures $1 \mathrm{~A}, \mathbf{B}$ ). rgQL90 only replicated in the spleen and lungs with a mean titer of $2.5 \log _{10} \mathrm{EID}_{50}$ and $5.25 \log _{10} \mathrm{EID}_{50}$, respectively (Table 2 ). The $\mathrm{MLD}_{50}$ of $\mathrm{rgDK} 212$ was $1.17 \log _{10} \mathrm{EID}_{50}$ and the MLD 50 of rgQL90 was $4.17 \log _{10} \mathrm{EID}_{50}$ (Table 3). rgDK212 and rgQL90 exhibited similar properties to their original viruses in terms of viral replication and $\mathrm{MLD}_{50}$.

\section{THE SWAP OF PB2 COULD DRAMATICALLY DECREASE THE VIRULENCE OF DK212 IN MICE}

To detect the pathogenicity of a virus-bearing single segment swap, mice were intranasally infected with the corresponding virus at a dose of $10^{6} \mathrm{EID}_{50}$. Virus $212-90 \mathrm{~PB} 2$ only caused $16.15 \%$ body weight loss and caused $60 \%$ mice to die (Figures 2A,B). The 212-90PB2 was only detected in the lungs, and the titer was significantly lower than that of $\operatorname{rgDK} 212$ (Table 2). The MLD 50 of 212-90PB2 virus was 1896-fold lower than that of DK212

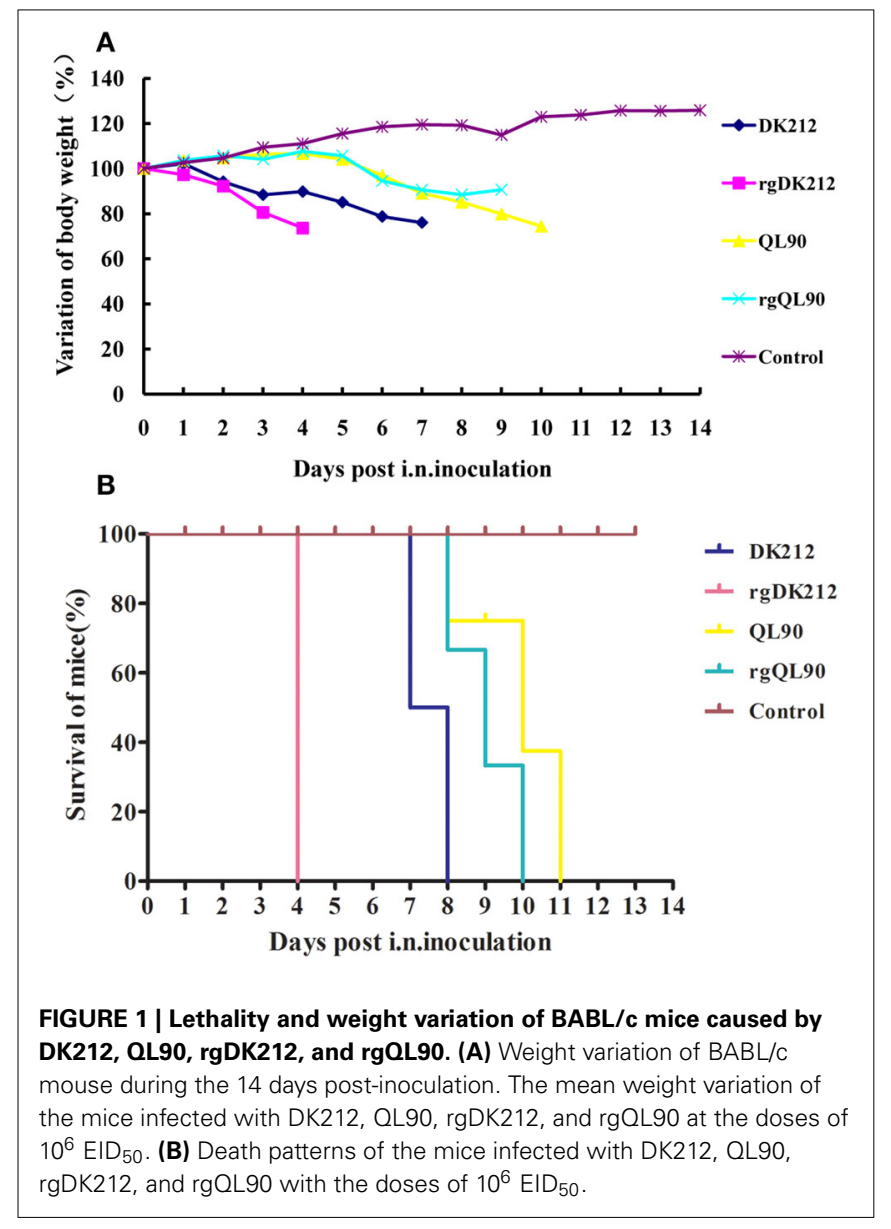

(Table 3). The PB2 of DK212 was crucial to its high virulence in mice.

\section{THE SWAP OF PA-NA AND M COULD SLIGHTLY DECREASE THE VIRULENCE OF DK212 IN MICE}

Besides PB2, the swap of PA-NA and M slightly attenuated the virus. 212-90PA, 212-90NA, and 212-90M caused 26.85-28.44\% body weight loss and killed all mice by $8-10$ DPI. Most viruses caused a systemic infection and then replicated. The mean titer was 1.08-5.75 $\log _{10} \mathrm{EID}_{50}$ and the MLD 50 was between 2.045 and 2.375. The virulence of these viruses was attenuated 7.5516.14 folds as compared to rgDK212 (Tables 2, 3). Notably, the $212-90 \mathrm{M}$ virus displayed no replication in the brain and lower replication in the kidneys and lungs $(p<0.05)$.

\section{THE SWAP OF PB1, NP AND NS MAINTAINS THE VIRULENCE OF DK212 IN MICE}

The chimeric viruses 212-90PB1, 212-90NP, and 212-90NS caused $27.46-29.43 \%$ body weight loss and killed all mice by $7-$ 8 DPI. Similar to DK212, these three chimeric viruses replicated in four organs and the mean titer was $1.58-6.75 \log _{10} \mathrm{EID}_{50}$. The replication titer of $212-90 \mathrm{NS}$ in the kidneys was higher than that of $\operatorname{rgDK} 212(p<0.05)$. The MLD 50 values of these three viruses were between 1.167 and 1.35 , and maintained similar virulence to $\operatorname{rgDK} 212$. 
Table 2 | Virus titers in organs of BABL/c mice at 3 days post-intranasal inoculation of viruses.

\begin{tabular}{|c|c|c|c|c|}
\hline \multirow[t]{2}{*}{ Viruses } & \multicolumn{4}{|c|}{$\begin{array}{l}3 \text { days post i.n. inoculation } \\
\left(\log _{10} \mathrm{EID}_{50} / \text { tissue } / 0.1 \mathrm{~mL}\right) \pm \mathrm{SD}\end{array}$} \\
\hline & Brain & Spleen & Kidney & Lung \\
\hline DK212 & $2.58 \pm 0.29^{a}$ & $1.67 \pm 1.15^{\mathrm{a}}$ & $2.92 \pm 0.29^{a}$ & $6.25 \pm 0$ \\
\hline rgDK212 & $2.33 \pm 0.63$ & $3.5 \pm 0.66$ & $2.25 \pm 0.5$ & $6.58 \pm 0.52$ \\
\hline 212-90PB2 & $<^{b}$ & $<^{\mathrm{b}}$ & $<^{\mathrm{b}}$ & $4.75 \pm 0.5^{b}$ \\
\hline 212-90PB1 & $1.58 \pm 1.01$ & $2.92 \pm 0.76$ & $2.75 \pm 0.43$ & $6.42 \pm 0.76$ \\
\hline 212-90PA & $1.83 \pm 0.88$ & $4.08 \pm 0.29$ & $2.42 \pm 0.76$ & $5.67 \pm 0.38$ \\
\hline $212-90 \mathrm{HA}$ & $1.25 \pm 0.43$ & $1.92 \pm 0.58^{b}$ & $<^{\mathrm{b}}$ & $6.58 \pm 0.29$ \\
\hline $212-90 N P$ & $1.92 \pm 1.15$ & $3.17 \pm 0.14$ & $2.75 \pm 0.5$ & $5.58 \pm 1.26$ \\
\hline 212-90NA & $1.25 \pm 0.43$ & $2.42 \pm 1.04$ & $2.83 \pm 0.52$ & $5.75 \pm 0.43$ \\
\hline $212-90 M$ & $<^{\mathrm{b}}$ & $1.08 \pm 0.14^{b}$ & $1.42 \pm 0.72^{b}$ & $5.42 \pm 0.29^{b}$ \\
\hline $212-90 N S$ & $2.92 \pm 0.29$ & $3 \pm 0.75$ & $3.17 \pm 0.14^{c}$ & $6.75 \pm 0$ \\
\hline 212-GIn39Lys & $1.25 \pm 0.43$ & $3.83 \pm 0.14$ & $3.08 \pm 0.14^{d}$ & $7 \pm 0$ \\
\hline 212-Ile649Val & $2.17 \pm 1.13$ & $2.75 \pm 1.39$ & $2.17 \pm 0.14$ & $6.92 \pm 0.14$ \\
\hline 212-Thr684Ala & $1.75 \pm 0.66$ & $2.67 \pm 1.18$ & $1.08 \pm 0.14^{\mathrm{e}}$ & $6.92 \pm 0.14$ \\
\hline 212-Ser715Asn & $1.33 \pm 0.58$ & $3.25 \pm 1.9$ & $2.08 \pm 0.76$ & $6.67 \pm 0.38$ \\
\hline QL90 & $<$ & $3 \pm 1.52$ & $<$ & $5.83 \pm 0.52$ \\
\hline rgQL90 & $<$ & $2.5 \pm 1.39$ & $<$ & $5.25 \pm 0.43$ \\
\hline 90-212PB2 & $<$ & $2.75 \pm 0.87$ & $<$ & $5.25 \pm 0.43$ \\
\hline 90-212PB1 & $<$ & $<^{\dagger}$ & $<$ & $4.08 \pm 0.14^{f}$ \\
\hline 90-212PA & $<$ & $2.83 \pm 1.59$ & $1.92 \pm 1.59$ & $5.25 \pm 0.5$ \\
\hline $90-212 \mathrm{HA}$ & $1.42 \pm 0.72$ & $3.67 \pm 0.38$ & $2.33 \pm 0.95^{9}$ & $6.17 \pm 0.14^{g}$ \\
\hline 90-212NP & $<$ & $2.17 \pm 1.01$ & $<$ & $5.08 \pm 0.14$ \\
\hline 90-212NA & $<$ & $3.75 \pm 0.43$ & $1.92 \pm 0.29$ & $5.75 \pm 0.5$ \\
\hline $90-212 M$ & $1.08 \pm 0.14$ & $2.92 \pm 1.01$ & $1.75 \pm 0.5$ & $5.42 \pm 0.29^{g}$ \\
\hline 90-212NS & $1.83 \pm 0.88^{9}$ & $3.08 \pm 0.76$ & $1.58 \pm 1.01$ & $6.17 \pm 0.52^{9}$ \\
\hline 90-Lys39GIn & $<$ & $<^{h}$ & $<$ & $5.08 \pm 1.04$ \\
\hline 90-Val649lle & $<$ & $<^{h}$ & $<$ & $5.75 \pm 0.5$ \\
\hline 90-Ala684Thr & $<$ & $1.33 \pm 0.58$ & $1.08 \pm 0.14$ & $4.92 \pm 0.14$ \\
\hline 90-Asn715Ser & $<$ & $<^{h}$ & $<$ & $3.58 \pm 0.58^{h}$ \\
\hline
\end{tabular}

"<" means no virus was detected from the undiluted sample in three embryonated hen eggs. Virus titers are expressed as means \pm standard deviation in $\log _{10} E / D_{50} /$ tissue $/ 0.1 \mathrm{~mL}$

a The titer of DK212 is higher than that of QL90(P < 0.05).

${ }^{b}$ The titer of chimeric viruses is lower than that of $\operatorname{rgDK} 212(P<0.05)$.

${ }^{c}$ The titer of chimeric viruses is higher than that of rgDK212 $(P<0.05)$

${ }^{d}$ The titer of mutants is higher than that of rgDK212 $(P<0.05)$.

${ }^{e}$ The titer of mutants is lower than that of rgDK212 $(P<0.05)$.

${ }^{f}$ The titer of chimeric viruses is lower than that of rgQL90 $(P<0.05)$.

$g$ The titer of chimeric viruses is higher than that of rgQL90 $(P<0.05)$.

${ }^{h}$ The titer of mutants is lower than that of rgQL90 $(P<0.05)$.

\section{THE SWAP OF HA SLIGHTLY INCREASED THE VIRULENCE OF DK212 IN MICE}

The chimeric virus $212-90 \mathrm{HA}$ caused $28.23 \%$ body weight loss and killed all mice at 6 DPI. Although the $\mathrm{MLD}_{50}$ of 212-90HA was 0.375 , which is 6.19 -fold higher than $\operatorname{rgDK} 212,212-90 \mathrm{HA}$ replicated in the brain, spleen and lung, Mean titer was 1.25-6.58 $\log _{10} \mathrm{EID}_{50}$ and the replication titer in the spleen was lower than $\operatorname{rgDK} 212(p<0.05)$.

\section{THE SWAP OF PB2 OBVIOUSLY INCREASED THE VIRULENCE OF OL9O IN MICE}

The $90-212 \mathrm{~PB} 2$ virus caused $17.53 \%$ body weight loss and killed all the mice at $8 \mathrm{DPI}$ at a dose of $10^{6} \mathrm{EID}_{50}$ (Figures $2 \mathrm{C}, \mathrm{D}$ ).
Table 3 | The MLD 50 of the wild-type viruses and their chimeric viruses as well as mutants.

\begin{tabular}{|c|c|c|c|}
\hline Viruses & $\begin{array}{c}\text { MLD }_{50} \\
\left(\log _{10} \mathrm{EID}_{50}\right)\end{array}$ & Viruses & $\begin{array}{c}\text { MLD }_{50} \\
\left(\log _{10} \mathrm{EID}_{50}\right)\end{array}$ \\
\hline DK212 & 1.5 & QL90 & 4.167 \\
\hline rgDK212 & 1.167 & rgOL90 & 4.17 \\
\hline 212-90PB2 & 4.445 & 90-212PB2 & 2.4 \\
\hline 212-90PB1 & 1.167 & 90-212PB1 & 3.445 \\
\hline 212-90PA & 2.045 & 90-212PA & 6.25 \\
\hline $212-90 \mathrm{HA}$ & 0.375 & $90-212 \mathrm{HA}$ & 4.167 \\
\hline $212-90 N P$ & 1.375 & 90-212NP & 4.445 \\
\hline $212-90 N A$ & 2.167 & 90-212NA & 4.167 \\
\hline $212-90 M$ & 2.375 & $90-212 M$ & 4.276 \\
\hline $212-90 N S$ & 1.167 & $90-212 N S$ & 2.045 \\
\hline 212-GIn39Lys & 3.6 & 90-Lys39 Gln & 4.75 \\
\hline 212-Ile649Val & 2.464 & 90-Val649 Ile & 5.25 \\
\hline 212-Thr684Ala & 3.75 & 90-Ala684Thr & 5 \\
\hline 212-Ser715Asn & 4.6 & 90-Asn715Ser & 4.625 \\
\hline
\end{tabular}

The $50 \%$ mouse lethal dose $\left(M L D_{50}\right)$ was evaluated by infecting groups of five mice with 10-fold serial dilutions, from 1 EID 50 to $10^{6}$ EID 50 . Mice were investigated dailyand weighed for 14 days. Mice that lost body weight over $30 \%$ were euthanized. MLD 50 were calculated with Reed-Muench method.

Although 90-212PB2 had similar replication patterns as rgQL90, the virulence of $90-212 \mathrm{~PB} 2$ was $58.88\left(10^{1.77}\right)$-fold higher than that of rgQL90 (Tables 2, 3).

\section{THE NS GENE OF DK212 SIGNIFICANTLY ENHANCED PATHOGENICITY OF OL9O IN MICE}

90-212NS viruses caused $21.32 \%$ body weight loss and killed all mice at 9 DPI at a dose of $10^{6} \mathrm{EID}_{50}$. The swap of NS enabled the QL90 virus to replicate in the brain, kidneys and lung with a titer higher than rgQL90 $(p<0.05)$ (Table 2). In addition, the virulence of $90-212 \mathrm{NS}$ in mice was $133.35\left(10^{2.125}\right)$-fold higher than that of rgQL90 (Table 3).

\section{THE PB1 GENE OF DK212 SLIGHTLY INCREASED PATHOGENICITY OF OL9O IN MICE}

90-212PB1 caused $12.19 \%$ body weight loss and killed all mice at 9 DPI at a dose of $10^{6}$ EID $_{50}$. Compared to rgQL90, 90-212PB1 showed no detected replication in the spleen and had a lower replication titer in the lungs with $4.08 \log _{10} \operatorname{EID}_{50}(p<0.05)$. However, the virulence of 90-212PB1 was 5.31-fold higher than that of rgQL90.

\section{THE SWAP OF HA, NP, NA, AND M MAINTAIN THE VIRULENCE OF OL90 IN MICE}

90-212HA, 90-212NA, and 90-212M caused 14.77-15.26\% body weight loss and killed all mice at $8-10$ DPI, at a dose of $10^{6}$ EID $_{50}$. These three viruses showed replication in multiple organs with a titer of 1.08-6.17 $\log _{10}$ EID $_{50}$. The titer of 90-212HA in the kidneys was higher than that of rgQL90 $(p<0.05)$ (Table 2). The $\mathrm{MLD}_{50}$ of these three viruses were 4.167-4.276. The 90-212NP virus at most caused $25.64 \%$ body weight loss and killed $60 \%$ of mice (Figures 2C,D). 90-212NP only replicated in the spleen and lung. The $\mathrm{MLD}_{50}$ of $90-212 \mathrm{NP}$ was 4.445 (Table 3 ). 

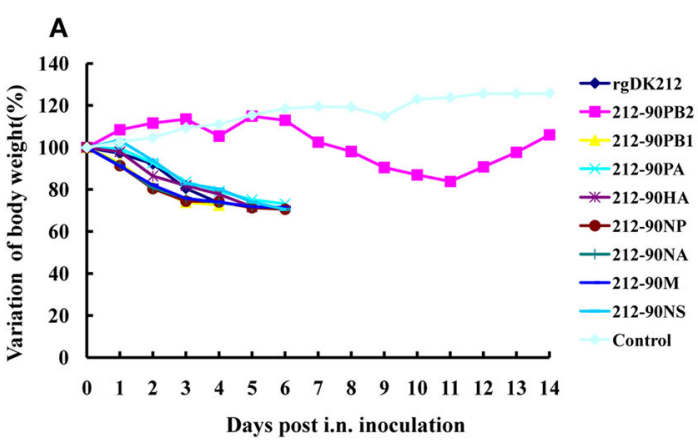

\section{B}

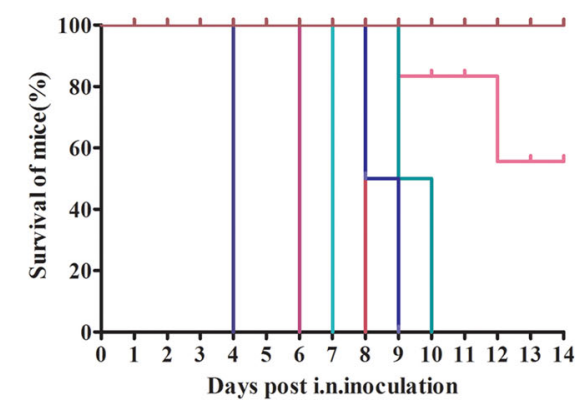

+ rgDK212
$+212-90 \mathrm{~PB} 2$
$+\quad 212-90 \mathrm{~PB} 1$
$+212-90 \mathrm{PA}$
$+212-90 \mathrm{HA}$
$+212-90 \mathrm{NP}$
$+212-90 \mathrm{NA}$
$+212-90 \mathrm{M}$
$+212-90 \mathrm{NS}$
+ Control

FIGURE 2 | Lethality and weight variation of $B A B L / c$ mice caused by rgDK212, rgQL90, and their chimeric viruses. $(A, C)$ Weight variation of $\mathrm{BABL} / \mathrm{c}$ mouse during the 14 days post-inoculation. The mean weight variation of the mice infected with rgDK212, rgQL90 and their and chimeric
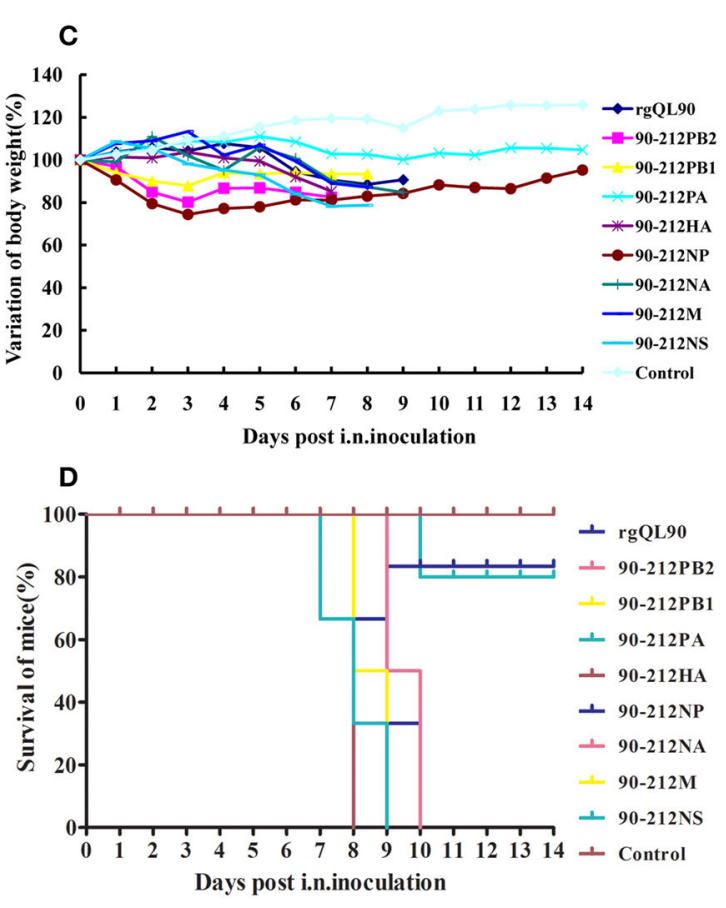

viruses of which one gene was replaced with the corresponding that of QL90, at the doses of $10^{6}$ EID $_{50}$. (B,D) Death patterns of the mice infected with rgDK212, rgQL90and their chimeric viruses, with the doses of $10^{6} \mathrm{EID}_{50}$.

\section{THE SWAP OF PA SIGNIFICANTLY DECREASED THE VIRULENCE OF QL90 IN MICE}

90-212PA had no obvious effect on body weight, and killed $20 \%$ of mice at a dose of $10^{6} \mathrm{EID}_{50}$ (Figures 2C,D). 90-212PA replicated in the spleen, kidneys and lungs with a titer of 1.92$5.25 \log _{10} \mathrm{EID}_{50}$ (Table 2). The MLD 50 of 90-212PA was 6.25, $120.23\left(10^{2.08}\right)$-fold lower than that of rgQL90 (Table 3 ).

\section{THE PB2 715SER MAINLY DECIDED THE HIGH VIRULENCE OF DK212 IN MICE}

To further determine the PB2 differences between these two viruses in pathogenicity to mice, we selected four single sites to generate mutants with a single amino acid swap, and detected their pathogenicity in mice. The 212-Gln39Lys, 212-Ile649Val, 212-Thr684Ala, and 212-Ser715Asn viruses caused 25.57-29.24\% body weight loss, and killed all the mice at 6-9 DPI. These four mutant strains could replicate in multiple organs with a titer of 1.08-7 $\log _{10}$ EID $_{50}$. The titer of 212-Thr684Ala in the kidneys was lower than that of $\operatorname{rgDK} 212(p<0.05)$. The $\mathrm{MLD}_{50}$ of these four viruses were 2.464-4.6, and were 19.82-2710.19-fold lower than rgDK212. Notably, the Ser715Asn mutation sharply decreased the virulence of rgDK212 in mice (2710.19-fold) (Figures 3A,B, Tables 2, 3). These results indicated that 715 Ser made a great contribution to the high pathogenicity of DK212 in mice.

\section{THE SINGLE AMINO ACID MUTATION DECREASED THE VIRULENCE OF QL9O IN MICE}

The 90-Lys39Gln, 90-Val649Ile, 90-Ala684Thr and 90-Asn715Ser caused $2.12 \%-29.48 \%$ body weight loss, and killed $40-100 \%$ of mice. 90-Ala684Thr could replicate in the spleen and kidneys, but the other three mutants only replicated in the lungs with a titer of 3.58-5.75 $\log _{10} \mathrm{EID}_{50}$, at a dose of $10^{6} \mathrm{EID}_{50}$. The results of $\mathrm{MLD}_{50}$ indicated the respective virulence of these four viruses were 2.19-38.02 folds lower than that of rgQL90 (Figures 3C,D, Tables 2, 3).

\section{THE PB2 OF DK212 WAS INVOLVED IN HIGH POLYMERASE ACTIVITY}

To compare the PB2 role of these two viruses in polymerase complexes, polymerase activity assay was conducted. The activity of polymerase complexes of DK212 was 85-fold higher than QL90 in $293 \mathrm{~T}$ cells at $37^{\circ} \mathrm{C}$. After the swap of PB2 between these two viruses, 90-212PB2 polymerase complex activity was 26 -fold higher than QL90 at $37^{\circ} \mathrm{C}$. In contrast, the activity of $212-90 \mathrm{~PB} 2$ complex was 11-fold lower than that of the DK212 complex (Figure 4). These results indicated that the PB2 gene was heavily involved in the discrepancy between the polymerase activity levels of these two viruses in human $293 \mathrm{~T}$ cells at $37^{\circ} \mathrm{C}$.

\section{DISCUSSION}

H5N1 highly pathogenic avian influenza virus could be transmitted to ferrets by aerosol droplets due to the acquisition of some mutations in HA and PB2 in lab experiments. This kind of novel virus may aggravate the threat to public health posed by H5N1 HPAIV. Therefore, studying the molecular mechanism of the pathogenicity of $\mathrm{H} 5 \mathrm{~N} 1$ virus in mammalian models is still emergent and necessary.

The $\mathrm{PB} 2$ protein plays an important role in pathogenicity. Mutation of Glu 627Lys or 701Asn in PB2 increases the 

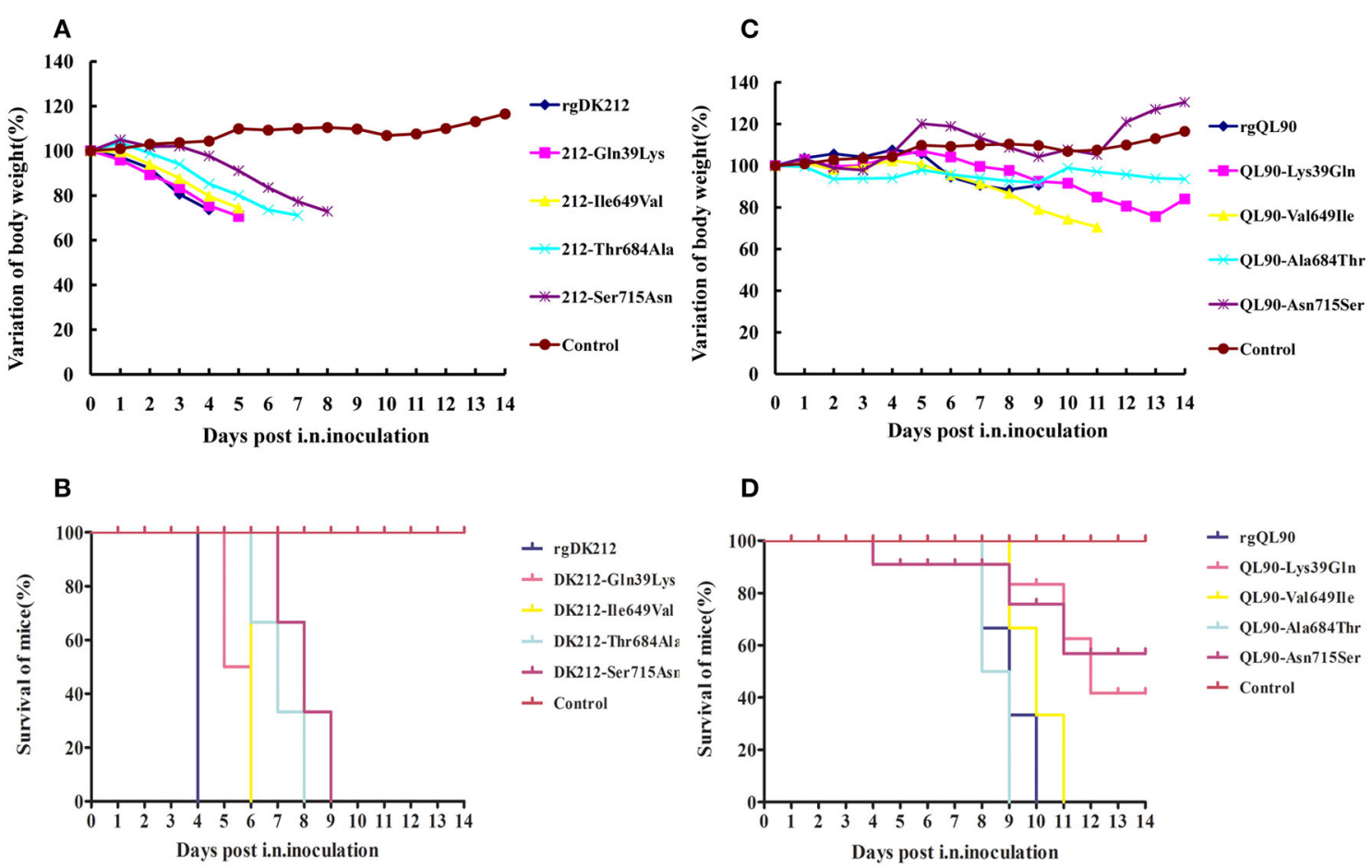

FIGURE 3 | Lethality and weight variation of $B A B L / c$ mice caused by rgDK212, rgOL90, and their four mutants. $(A, C)$ Weight variation of $\mathrm{BABL} / \mathrm{c}$ mouse during the 14 days post-inoculation. The mean weight variation of the mice infected with rgDK212, rgQL90 and their single

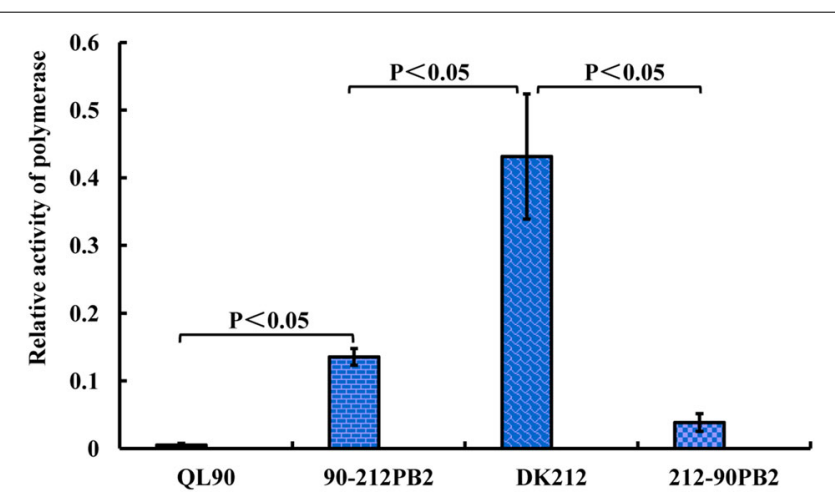

FIGURE 4 | Relative activity of polymerase complexes of QL90, 90-212PB2, DK212, and 212-90PB2. The 293T cells were transfected with $\mathrm{pHH}-\mathrm{NP}, \mathrm{pHH}-\mathrm{PA}$, $\mathrm{pHH}-\mathrm{PB} 1$, and $\mathrm{pH}-\mathrm{PB} 2$, along with the luciferase and renilla reporter gene plasmids. Transfected cells were cultured at 37 for $24 \mathrm{~h}$, and luciferase and renilla production were determined. The relative activity of polymerase complexes was expressed as the production of luciferase dividing the production of renilla. The results were calculated as means \pm standard deviations from three independent experiments, by using of SPASS (version 11.5).

pathogenesis of viruses in mammalian hosts (Li et al., 2005; de Jong et al., 2013) and transmissibility between mammalian models (Gabriel et al., 2008; Gao et al., 2009; Steel et al., 2009). In addition, mutation Gln591Lys of PB2 could compensate for the lack of PB2-627Lys and increase the virulence of an avian

H5N1 influenza virus in mice (Yamada et al., 2010). In this study, the amino acids at positions 591, 627, and 701 in PB2 were Gln, Glu, and Asp for DK212 and QL90, but both of them still had high levels of pathogenicity in mice. The results support the contribution of the virus without 627Lys or 701Asn or Gln591Lys could be compensated for by other mutations at other sites of PB2. The virulence of DK212 showed 464-fold higher than that of QL90 in mice. The swap of PB2 sharply decreased the virulence of rgDK212 (1896-fold) and limited replication of rgDK212 to the lungs only and with lower titer in mice. In contrast, the swap of PB2 dramatically increased the virulence of rgQL90 in mice (60-fold). The results indicated PB2 was a key factor for determining differences in the virulence of DK212 and QL90 in mice.

The PB2 protein is also involved in polymerase activity and nuclear localization. PB2 acts as a "cap snatching" function in polymerase complex of influenza. The cap binding sites of PB2 locates in residues 32-483. The C-terminal of PB2 (residues 538-759) interacts with host proteins. Introduction of mutations in the PB2 gene, such as 339 Lys, 271Ala, 627Lys, 591Lys/Arg, 701Asn, and 714Arg enhance polymerase activity in mammalian cells (Gabriel et al., 2005; Bussey et al., 2010; Yamada et al., 2010; Liu et al., 2013). In this study, the different amino acids include Gln39Lys, near the domain of PB2 which binds to PB1; Thr339Lys, Arg340Lys, and Gly368Arg, locate in "cap snatching"; Ile649Val, Thr684Ala, and Ser715Asn, locate in the domain in which PB2 reacts with the host protein. Mutations were located in 
or near the regions in which proteins or protein/RNA interactions affected the activity of polymerase complex. Swapping the PB2 gene significantly enhanced the polymerase activity of QL90 (26fold) and sharply reduced the activity polymerase complex of DK212 (11-fold) in human $293 \mathrm{~T}$ cells at $37^{\circ} \mathrm{C}$. These results indicated that $\mathrm{PB} 2$ of DK212 played an important role in maintaining high polymerase activity. The different properties of the PB2 in DK212 and QL90 might account for their differing replication ability in mice.

The NS1 protein is an important factor in virulence by antagonizing IFN- $\alpha / \beta$ production for avian influenza viruses in a mammalian model (Cheung et al., 2002; Quinlivan et al., 2005; Li et al., 2006). NS1 could reduce the production of IFN- $\alpha / \beta$ by binding to dsRNA or retinoic-acid inducible gene I (RIG-I) ligands to block activation of $2^{\prime}-5^{\prime}$-oligoadenylatesynthetase (OAS) and protein kinase R (PKR). NS1 also could suppress IFN premRNA processing and mRNA nuclear exports, by binding to the cellular pre-mRNA processing protein cleavage and polyadenylation specificity factor (CPSF30) (Hale et al., 2008; Zhang et al., 2013). The H5N1 virus with some mutation, such as Asp92Glu, Pro42Ser, Leu103Phe, and Ile106Met in NS1, could enhance the ability to inhibit the IFN- $\alpha / \beta$ production and increase viral replication, resulting in high pathogenicity in pigs or mice (Seo et al., 2002; Twu et al., 2007; Jiao et al., 2008). In addition, the C-terminus of the NS1, PDZ-ligand domain was involved with the virulence level (Jackson et al., 2008). There were 4 amino acid discrepancies in NS1 and NS2 between DK212 and QL90, respectively. Swapping the NS gene could dramatically enhance the pathogenicity of rgQL90 (133.35-fold) and enable rgQL90 replication in the brain. The swap of NS gene did not obviously affect the pathogenicity and replication of DK212 in mice. These findings indicated the differences in NS protein between DK212 and QL90 could possibly play a key role in determining virulence. In addition, the higher activity of the polymerase complex of DK212 could counteract the effects of swapping the NS gene and maintaining the virulence of DK212 in mice.

HA protein serves as binding and fusogenic function during influenza A virus infection. Amino acid substitutions in HA which affect the receptor binding preference may alter tissue tropism and change virulence in the host (Schrauwen et al., 2014). The multi-basic cleavage site was critical for the spread of the $\mathrm{H} 5 \mathrm{~N} 1$ virus to the mouse brain following intranasal infection (Hatta et al., 2001). In this study, despite DK212 and QL90 having the same multi-basic cleavage site, there were 7 amino acid discrepancies in HA. QL90 was not similar to DK212 and only replicated in the spleen and lungs. The swap of HA increased the virulence of rgDK212 19.72-fold but also made rgDK212 lose the ability to replicate in the kidneys. Meanwhile, the swap of HA enabled rgQL90 replication in the brain and kidneys. These results indicated that $\mathrm{HA}$ of DK212 was important for the virus in maintaining the multiple-tissue tropism.

Non-coding sequences at the vRNA segments were parts of the viral RNA packing signals, mutation in no-coding area would affect viral RNA synthesis (Muster et al., 1991; Zheng et al., 1996; Watanabe et al., 2003; Liang et al., 2005; Ng et al., 2008). In addition, the coding region located at the end of the neuraminidase segment played an important role in RNA segment incorporation into virion (Fujii et al., 2005). 22 nucleic acids displayed differences in the non-coding and coding regions of the NA gene between DK212 and QL90. The differences in these nucleic acids of NA affected viral RNA synthesis and the formulation of virion, and subsequently attenuated the pathogenesis of DK212 virus in mice.

There were 7 amino acids discrepancy in PB2 between DK212 and QL90, which included three discrepancies at PB2 Ile649Val, Thr684Ala, and Ser715Asn located in the nuclear localization domain or host protein binding domain (Brown, 2000), and one discrepancy at Gln39Lys PB2, near the PA binding area (residues 1-35) (He et al., 2008; Sugiyama et al., 2009). Their mutation may disturb nuclear localization and interrupt the host's antiviral pathway to change the viral replication. Therefore, we chose these four sites to generate the single amino acid mutant. The virulence of 212-Gln39Lys, 212-Ile649Val, 212-Thr684Ala, and 212-Ser715Asn showed as being 19.82-2710.19-fold lower than in $\operatorname{rgDK} 212$. It is noteworthy that the Ser715Asn mutation dramatically decreased the virulence of DK212 by almost 2710.19-fold. Similar to rgDK212, the single amino acid swap decreased the virulence of rgQL90 in mice (2.19-38.02-fold). Asn715 Ser mutation made QL90 only able to replicate in the lungs with a lower titer. The Ser714Arg single mutation introduced into SC35 did not increase the virulence of the virus in mice, but 714Arg was essential for SC35M in maintaining high pathogenicity. PB2 714Arg worked together with other mutations for the adaptation of SC35M (Gabriel et al., 2005). Likewise, the Ser715Asn single mutation sharply decreased the virulence of DK212, but the Asn715Ser single mutation did not increase the pathogenicity of QL90. 715Ser was essential for maintaining high pathogenicity of DK212, but not for QL90.

In light of the present study, PB2 of DK212, which dramatically affected the polymerase activity, mainly contributed to the difference in virulence of DK212 and QL90 in mice. In addition, 715Ser in the $\mathrm{PB} 2$ protein played an important role in maintaining high pathogenicity of DK212 to mice.

\section{AUTHOR CONTRIBUTIONS}

Hailiang Sun conducted the experiments and analyzed the data and wrote the paper. Pengfei Cui participated in partial mouse experiment. Peirong Jiao, Yan Qi, Xiaokang Li, and Wenbao Qi provided technical instruction. Yafen Song and Chenggang $\mathrm{Xu}$ were involved in isolation of wild-type viruses. Ming Liao and Peirong Jiao desired the experiments and revised paper.

\section{ACKNOWLEDGMENTS}

This work was supported by grants from the Natural Science Foundation of Guangdong Province (No.10251064201000004, No.10151064201000021), the National Natural Science Foundation of China (No.31172343), the Science and Technology Projects of Guangdong Province (No. 2010B020307005), the Earmarked Fund for Modern Agro-Industry Technology Research System (nycytx-42-G3-03), and High-level Talents in University Project of Guangdong Province. 


\section{SUPPLEMENTARY MATERIAL}

The Supplementary Material for this article can be found online at: http://www.frontiersin.org/journal/10.3389/fmicb. 2015.00073/abstract

\section{REFERENCES}

Brown, E. G. (2000). Influenza virus genetics. Biomed. Pharmacother. 54, 196-209. doi: 10.1016/S0753-3322(00)89026-5

Bussey, K. A., Bousse, T. L., Desmet, E. A., Kim, B., and Takimoto, T. (2010). PB2 residue 271 plays a key role in enhanced polymerase activity of influenza A viruses in mammalian host cells. J. Virol. 84, 4395-4406. doi: 10.1128/JVI.02642-09

Chen, H., Bright, R. A., Subbarao, K., Smith, C., Cox, N. J., Katz, J. M., et al. (2007). Polygenic virulence factors involved in pathogenesis of 1997 Hong Kong H5N1 influenza viruses in mice. Virus Res. 128, 159-163. doi: 10.1016/j.virusres.2007.04.017

Chen, H., Deng, G., Li, Z., Tian, G., Li, Y., Jiao, P., et al. (2004). The evolution of H5N1 influenza viruses in ducks in southern China. Proc. Natl. Acad. Sci. U.S.A. 101, 10452-10457. doi: 10.1073/pnas.0403212101

Chen, H., Li, Y., Li, Z., Shi, J., Shinya, K., Deng, G., et al. (2006). Properties and dissemination of $\mathrm{H} 5 \mathrm{~N} 1$ viruses isolated during an influenza outbreak in migratory waterfowl in western China. J. Virol. 80, 5976-5983. doi: 10.1128/JVI.00110-06

Chen, H., Smith, G. J., Zhang, S. Y., Qin, K., Wang, J., Li, K. S., et al. (2005). Avian flu: H5N1 virus outbreak in migratory waterfowl. Nature 436, 191-192. doi: 10.1038/nature03974

Cheung, C. Y., Poon, L. L., Lau, A. S., Luk, W., Lau, Y. L., Shortridge, K. F., et al. (2002). Induction of proinflammatory cytokines in human macrophages by influenza A (H5N1) viruses: a mechanism for the unusual severity of human disease? Lancet 360, 1831-1837. doi: 10.1016/S0140-6736(02)11772-7

Conenello, G. M., Zamarin, D., Perrone, L. A., Tumpey, T., and Palese, P. (2007). A single mutation in the PB1-F2 of H5N1 (HK/97) and 1918 influenza A viruses contributes to increased virulence. PLoS Pathog. 3:e141. doi: 10.1371/journal.ppat.0030141

de Jong, R. M., Stockhofe-Zurwieden, N., Verheij, E. S., de Boer-Luijtze, E. A., Ruiter, S. J., de Leeuw, O. S., et al. (2013). Rapid emergence of a virulent PB2 E627K variant during adaptation of highly pathogenic avian influenza H7N7 virus to mice. Virol. J. 10:276. doi: 10.1186/1743-422X-10-276

de Wit, E., Munster, V. J., van Riel, D., Beyer, W. E., Rimmelzwaan, G. F., Kuiken, T., et al. (2010). Molecular determinants of adaptation of highly pathogenic avian influenza H7N7 viruses to efficient replication in the human host. J. Virol. 84, 1597-1606. doi: 10.1128/JVI.01783-09

Fan, S., Deng, G., Song, J., Tian, G., Suo, Y., Jiang, Y., et al. (2009). Two amino acid residues in the matrix protein $\mathrm{M} 1$ contribute to the virulence difference of $\mathrm{H} 5 \mathrm{~N} 1$ avian influenza viruses in mice. Virology 384, 28-32. doi: 10.1016/j.virol.2008.11.044

Fujii, K., Fujii, Y., Noda, T., Muramoto, Y., Watanabe, T., Takada, A., et al. (2005). Importance of both the coding and the segment-specific noncoding regions of the influenza A virus NS segment for its efficient incorporation into virions. J. Virol. 79, 3766-3774. doi: 10.1128/JVI.79.6.3766-3774.2005

Gabriel, G., Dauber, B., Wolff, T., Planz, O., Klenk, H. D., and Stech, J. (2005) The viral polymerase mediates adaptation of an avian influenza virus to a mammalian host. Proc. Natl. Acad. Sci. U.S.A. 102, 18590-18595. doi: 10.1073/pnas.0507415102

Gabriel, G., Herwig, A., and Klenk, H. D. (2008). Interaction of polymerase subunit PB2 and NP with importin alphal is a determinant of host range of influenza A virus. PLoS Pathog. 4:e11. doi: 10.1371/journal.ppat.0040011

Gao, Y., Zhang, Y., Shinya, K., Deng, G., Jiang, Y., Li, Z., et al. (2009). Identification of amino acids in $\mathrm{HA}$ and $\mathrm{PB} 2$ critical for the transmission of $\mathrm{H} 5 \mathrm{~N} 1$ avian influenza viruses in a mammalian host. PLoS Pathog. 5:e1000709. doi: 10.1371/journal.ppat.1000709

Hale, B. G., Randall, R. E., Ortin, J., and Jackson, D. (2008). The multifunctional NS1 protein of influenza A viruses. J. Gen. Virol. 89, 2359-2376. doi: 10.1099/vir.0.2008/004606-0

Hatta, M., Gao, P., Halfmann, P., and Kawaoka, Y. (2001). Molecular basis for high virulence of Hong Kong H5N1 influenza A viruses. Science 293, 1840-1842. doi: 10.1126/science. 1062882

Hatta, M., Hatta, Y., Kim, J. H., Watanabe, S., Shinya, K., Nguyen, T., et al. (2007). Growth of H5N1 influenza A viruses in the upper respiratory tracts of mice. PLoS Pathog. 3:e133. doi: 10.1371/journal.ppat. 0030133

He, X., Zhou, J., Bartlam, M., Zhang, R., Ma, J., Lou, Z., et al. (2008). Crystal structure of the polymerase $\mathrm{PA}(\mathrm{C})-\mathrm{PB} 1(\mathrm{~N})$ complex from an avian influenza H5N1 virus. Nature 454, 1123-1126. doi: 10.1038/nature07120

Herfst, S., Schrauwen, E. J., Linster, M., Chutinimitkul, S., de Wit, E., Munster, V. J., et al. (2012). Airborne transmission of influenza A/H5N1 virus between ferrets. Science 336, 1534-1541. doi: 10.1126/science.1213362

Hoffmann, E., Neumann, G., Kawaoka, Y., Hobom, G., and Webster, R. G. (2000). A DNA transfection system for generation of influenza A virus from eight plasmids. Proc. Natl. Acad. Sci. U.S.A. 97, 6108-6113. doi: 10.1073/pnas.100133697

Hoffmann, E., Stech, J., Guan, Y., Webster, R. G., and Perez, D. R. (2001). Universal primer set for the full-length amplification of all influenza A viruses. Arch. Virol. 146, 2275-2289. doi: 10.1007/s007050170002

Imai, M., Watanabe, T., Hatta, M., Das, S. C., Ozawa, M., Shinya, K., et al. (2012). Experimental adaptation of an influenza H5 HA confers respiratory droplet transmission to a reassortant $\mathrm{H} 5 \mathrm{HA} / \mathrm{H} 1 \mathrm{~N} 1$ virus in ferrets. Nature 486, 420-428. doi: 10.1038/nature 10831

Jackson, D., Hossain, M. J., Hickman, D., Perez, D. R., and Lamb, R. A. (2008). A new influenza virus virulence determinant: the NS1 protein four C-terminal residues modulate pathogenicity. Proc. Natl. Acad. Sci. U.S.A. 105, 4381-4386. doi: 10.1073/pnas.0800482105

Jiao, P., Tian, G., Li, Y., Deng, G., Jiang, Y., Liu, C., et al. (2008). A single-aminoacid substitution in the NS1 protein changes the pathogenicity of $\mathrm{H} 5 \mathrm{~N} 1$ avian influenza viruses in mice. J. Virol. 82, 1146-1154. doi: 10.1128/JVI.01698-07

Li, Y., Shi, J., Zhong, G., Deng, G., Tian, G., Ge, J., et al. (2010). Continued evolution of $\mathrm{H} 5 \mathrm{~N} 1$ influenza viruses in wild birds, domestic poultry, and humans in China from 2004 to 2009. J. Virol. 84, 8389-8397. doi: 10.1128/JVI.00413-10

Li, Z., Chen, H., Jiao, P., Deng, G., Tian, G., Li, Y., et al. (2005). Molecular basis of replication of duck $\mathrm{H} 5 \mathrm{~N} 1$ influenza viruses in a mammalian mouse model. J. Virol. 79, 12058-12064. doi: 10.1128/JVI.79.18.12058-12064.2005

Li, Z., Jiang, Y., Jiao, P., Wang, A., Zhao, F., Tian, G., et al. (2006). The NS1 gene contributes to the virulence of $\mathrm{H} 5 \mathrm{~N} 1$ avian influenza viruses. J. Virol. 80, 11115-11123. doi: 10.1128/JVI.00993-06

Liang, Y., Hong, Y., and Parslow, T. G. (2005). cis-Acting packaging signals in the influenza virus PB1, PB2, and PA genomic RNA segments. J. Virol. 79, 10348-10355. doi: 10.1128/JVI.79.16.10348-10355.2005

Liu, Y., Qin, K., Meng, G., Zhang, J., Zhou, J., Zhao, G., et al. (2013). Structural and functional characterization of K339T substitution identified in the PB2 subunit cap-binding pocket of influenza A virus. J. Biol. Chem. 288, 11013-11023. doi: 10.1074/jbc.M112.392878

Maines, T. R., Chen, L. M., Matsuoka, Y., Chen, H., Rowe, T., Ortin, J., et al (2006). Lack of transmission of H5N1 avian-human reassortant influenza viruses in a ferret model. Proc. Natl. Acad. Sci. U.S.A. 103, 12121-12126. doi: 10.1073/pnas.0605134103

Muster, T., Subbarao, E. K., Enami, M., Murphy, B. R., and Palese, P. (1991). An influenza A virus containing influenza B virus 5' and 3' noncoding regions on the neuraminidase gene is attenuated in mice. Proc. Natl. Acad. Sci. U.S.A. 88, 5177-5181. doi: 10.1073/pnas.88.12.5177

Neumann, G., Shinya, K., and Kawaoka, Y. (2007). Molecular pathogenesis of H5N1 influenza virus infections. Antivir. Ther. 12, 617-626.

Ng, S. S., Li, O. T., Cheung, T. K., Malik Peiris, J. S., and Poon, L. L. (2008). Heterologous influenza vRNA segments with identical non-coding sequences stimulate viral RNA replication in trans. Virol. J. 5:2. doi: 10.1186/1743-422X5-2

Quinlivan, M., Zamarin, D., Garcia-Sastre, A., Cullinane, A., Chambers, T., and Palese, P. (2005). Attenuation of equine influenza viruses through truncations of the NS1 protein. J. Virol. 79, 8431-8439. doi: 10.1128/JVI.79.13.8431-8439.2005

Reed, L. J., and Muench, H. (1938). A simple method of estimating fifty percent endpoints. Am. J. Epidemiol. 27, 5.

Schrauwen, E. J., de Graaf, M., Herfst, S., Rimmelzwaan, G. F., Osterhaus, A. D., and Fouchier, R. A. (2014). Determinants of virulence of influenza A virus. Eur. J. Clin. Microbiol. Infect. Dis. 33, 479-490. doi: 10.1007/s10096-013-1984-8

Seo, S. H., Hoffmann, E., and Webster, R. G. (2002). Lethal H5N1 influenza viruses escape host anti-viral cytokine responses. Nat. Med. 8, 950-954. doi: $10.1038 / \mathrm{nm} 757$

Steel, J., Lowen, A. C., Mubareka, S., and Palese, P. (2009). Transmission of influenza virus in a mammalian host is increased by PB2 amino acids $627 \mathrm{~K}$ or 627E/701N. PLoS Pathog. 5:e1000252. doi: 10.1371/journal.ppat.1000252 
Sugiyama, K., Obayashi, E., Kawaguchi, A., Suzuki, Y., Tame, J. R., Nagata, K., et al. (2009). Structural insight into the essential PB1-PB2 subunit contact of the influenza virus RNA polymerase. EMBO J. 28, 1803-1811. doi: 10.1038/emboj.2009.138

Sun, H., Jiao, P., Jia, B., Xu, C., Wei, L., Shan, F., et al. (2011). Pathogenicity in quails and mice of $\mathrm{H} 5 \mathrm{~N} 1$ highly pathogenic avian influenza viruses isolated from ducks. Vet. Microbiol. 152, 258-265. doi: 10.1016/j.vetmic.2011.05.009

Tumpey, T. M., Maines, T. R., Van Hoeven, N., Glaser, L., Solorzano, A., Pappas, C., et al. (2007). A two-amino acid change in the hemagglutinin of the 1918 influenza virus abolishes transmission. Science 315, 655-659. doi: 10.1126/science. 1136212

Twu, K. Y., Kuo, R. L., Marklund, J., and Krug, R. M. (2007). The H5N1 influenza virus NS genes selected after 1998 enhance virus replication in mammalian cells. J. Virol. 81, 8112-8121. doi: 10.1128/JVI.00006-07

van Wielink, R., Harmsen, M. M., Martens, D. E., Peeters, B. P., Wijffels, R. H., and Moormann, R. J. (2012). Mutations in the M-gene segment can substantially increase replication efficiency of NS1 deletion influenza A virus in MDCK cells. J. Virol. 86, 12341-12350. doi: 10.1128/JVI.01725-12

Wan, X. F., Dong, L., Lan, Y., Long, L. P., Xu, C., Zou, S., et al. (2011). Indications that live poultry markets are a major source of human $\mathrm{H} 5 \mathrm{~N} 1$ influenza virus infection in China. J. Virol. 85, 13432-13438. doi: 10.1128/JVI.05266-11

Watanabe, T., Watanabe, S., Noda, T., Fujii, Y., and Kawaoka, Y. (2003). Exploitation of nucleic acid packaging signals to generate a novel influenza virus-based vector stably expressing two foreign genes. J. Virol. 77, 10575-10583. doi: 10.1128/JVI.77.19.10575-10583.2003

Yamada, S., Hatta, M., Staker, B. L., Watanabe, S., Imai, M., Shinya, K., et al. (2010). Biological and structural characterization of a host-adapting amino acid in influenza virus. PLoS Pathog. 6:e1001034. doi: 10.1371/journal.ppat. 1001034

Yen, H. L., Ilyushina, N. A., Salomon, R., Hoffmann, E., Webster, R. G., and Govorkova, E. A. (2007b). Neuraminidase inhibitor-resistant recombinant A/Vietnam/1203/04 (H5N1) influenza viruses retain their replication efficiency and pathogenicity in vitro and in vivo. J. Virol. 81, 12418-12426. doi: 10.1128/JVI.01067-07

Yen, H. L., Lipatov, A. S., Ilyushina, N. A., Govorkova, E. A., Franks, J., Yilmaz, N., et al. (2007a). Inefficient transmission of H5N1 influenza viruses in a ferret contact model. J. Virol. 81, 6890-6898. doi: 10.1128/JVI.00170-07

Zhang, H., Hale, B. G., Xu, K., and Sun, B. (2013). Viral and host factors required for avian $\mathrm{H} 5 \mathrm{~N} 1$ influenza A virus replication in mammalian cells. Viruses 5, 1431-1446. doi: 10.3390/v5061431

Zheng, H., Palese, P., and Garcia-Sastre, A. (1996). Nonconserved nucleotides at the 3' and 5' ends of an influenza A virus RNA play an important role in viral RNA replication. Virology 217, 242-251. doi: 10.1006/viro.1996.0111

Zhou, B., Li, Y., Halpin, R., Hine, E., Spiro, D. J., and Wentworth, D. E. (2011). PB2 residue 158 is a pathogenic determinant of pandemic $\mathrm{H} 1 \mathrm{~N} 1$ and $\mathrm{H} 5$ influenza a viruses in mice. J. Virol. 85, 357-365. doi: 10.1128/JVI.01694-10

Conflict of Interest Statement: The authors declare that the research was conducted in the absence of any commercial or financial relationships that could be construed as a potential conflict of interest.

Received: 04 November 2014; accepted: 21 January 2015; published online: 10 February 2015.

Citation: Sun H, Cui P, Song Y, Qi Y, Li X, Qi W, Xu C, Jiao P and Liao M (2015) PB2 segment promotes high-pathogenicity of H5N1 avian influenza viruses in mice. Front. Microbiol. 6:73. doi: 10.3389/fmicb.2015.00073

This article was submitted to Virology, a section of the journal Frontiers in Microbiology.

Copyright (C) 2015 Sun, Cui, Song, Qi, Li, Qi, Xu, Jiao and Liao. This is an openaccess article distributed under the terms of the Creative Commons Attribution License (CC BY). The use, distribution or reproduction in other forums is permitted, provided the original author(s) or licensor are credited and that the original publication in this journal is cited, in accordance with accepted academic practice. No use, distribution or reproduction is permitted which does not comply with these terms. 